\title{
Narratives of Identity: Understanding the Experiences of Adults with Hearing Loss who use Hearing Aids
}

\author{
Brittan A. Barker ${ }^{1 a}$, Kristina M. Scharp ${ }^{2 b}$, Shea A. Long ${ }^{1 \dagger}, \&$ \\ Caitlyn R. Ritter ${ }^{1 \dagger}$
}

${ }^{1}$ Department of Communicative Disorders and Deaf Education, Utah State University, Logan, Utah, USA.

a ORCiDs ID: 0000-0001-9327-7057

${ }^{2}$ Department of Language, Philosophy, and Communication Studies, Utah

State University, Logan, Utah, USA. ORCiDs ID: 0000-0002-9280-6313

${ }^{b}$ Dr. Scharp is now affiliated with the Department of Communication, University of Washington, Seattle, Washington, USA.

†Third and fourth authorship determined by a coin toss

Address correspondence to Brittan A. Barker, Department of Communicative Disorders and Deaf Education, Utah State University, 1000 Old Main, Logan, Utah 84322 USA.

E-mail: brittan.barker@usu.edu

\section{Financial Disclosures/Conflicts of Interest:}

There are no financial disclosures/conflicts of interest to report for this research.

The data that support the findings of this study are available on request from the corresponding author, BAB. The data are not publicly available due to their containing information that could compromise the privacy of research participants.

Keywords: hearing aids, identities, thematic narrative analysis, hearing loss, narrative sense making 


\begin{abstract}
Objective: We aimed to determine the identities that adults with hearing loss construct when telling stories about their experiences with hearing loss and hearing aids. Determining and understanding these identities is important because research shows that who a person believes themselves to be has implications for how they approach their healthcare, along with their emotional and physical wellbeing.
\end{abstract}

Design: We employed a qualitative narrative approach. We then used thematic narrative analysis to identify emergent identities across stories gathered from hearing aid users. These themes allowed us to assign emergent identities to the hearing-aid users.

Study Sample: Thirty adults with hearing loss who reported using their hearing aids during all waking hours.

Results: Five identities emerged from the hearing-aid users' narratives: 1) the satisfied user, 2) the overcomer, 3) the dispassionate user, 4) the frustrated and resigned user, and 5) the griever.

Conclusions: These findings are a first step to improving theoretical and clinical insights into the perspectives and experiences of satisfied hearing-aid users following diagnosis of their hearing loss and their hearing aid fittings. Such insights could ultimately improve hearing healthcare providers' abilities to employ person-centered care while helping adults with hearing loss seek out, implement, and adhere to treatment. 


\title{
Narratives of Identity: Understanding the Experiences of Adults with Hearing Loss who use Hearing Aids
}

\author{
Brittan A. Barker ${ }^{1 a}$, Kristina M. Scharp ${ }^{2 b}$, Shea A. Long ${ }^{1 \dagger}, \&$ \\ Caitlyn R. Ritter ${ }^{1 \dagger}$
}

${ }^{1}$ Department of Communicative Disorders and Deaf Education, Utah State University, Logan, Utah, USA.

a ORCiDs ID: 0000-0001-9327-7057

${ }^{2}$ Department of Language, Philosophy, and Communication Studies, Utah

State University, Logan, Utah, USA. ORCiDs ID: 0000-0002-9280-6313

${ }^{b}$ Dr. Scharp is now affiliated with the Department of Communication, University of Washington, Seattle, Washington, USA.

†Third and fourth authorship determined by a coin toss

Address correspondence to Brittan A. Barker, Department of Communicative Disorders and Deaf Education, Utah State University, 1000 Old Main, Logan, Utah 84322 USA.

E-mail: brittan.barker@usu.edu

\section{Financial Disclosures/Conflicts of Interest:}

There are no financial disclosures/conflicts of interest to report for this research.

The data that support the findings of this study are available on request from the corresponding author, BAB. The data are not publicly available due to their containing information that could compromise the privacy of research participants.

Keywords: hearing aids, identities, thematic narrative analysis, hearing loss, narrative sense making 


\section{Narratives of Identity: Understanding the Experiences of Adults with Hearing Loss who use Hearing Aids}

Approximately 37.5 million adults in the United States (U.S.) report some degree of hearing loss (HL; Blackwell et al. 2014). Without listening-device intervention, research shows there are a number of negative consequences that can stem from HL. These range from psychological issues (e.g., negative effects on quality of life and emotional wellbeing; Ciorba et al. 2012) to accelerated cognitive decline (Lin et al. 2013). However, research shows that these negative consequences are improved — and sometimes amerliorated—after patients adhere to a hearing aid (HA) treatment plan (Ferguson et al. 2017; Ivory et al. 2009; Johnson et al. 2016). Thus, it stands to reason, if healthcare providers could better understand the acceptance, experiences, and consistent use of HAs by more people with HL, they could also ensure better overall health for these individuals.

\section{Identity in a Healthcare Context}

A healthcare professional's understanding of a patient's identity has implications for both the approach to and quality of the services one provides (e.g., Charon 2006; Grenness et al. 2014; Thompson et al. 2003; Paddam et al. 2010; Petty 2017). A sound understanding of a patient's identity is also important when it comes to guiding their decision-making process during diagnosis and treatment - particularly when/if a patient perceives their choices to be helpful or hurtful to their health outcomes (Laplante-Lévesque et al. 2010). A professional's support throughout the individual's treatment process might prove important (McCormack \& Fortnum 2013) and can benefit the patient only if the healthcare provider recognizes and understands the patients' perception of themselves. 
A first step in discerning the identities of peolple with HL, who wear HAs, is to learn more about their perspectives of the diagnostic and treatment proceses. This information can be learned through narrative sensemaking (i.e. storytelling). "Patient narratives or stories offer the construction of meaning from experience, a therapeutic retelling of events, and valuable diagnostic information and details." (Gray 2009, p. 259) Furthermore, such stories provide insight into patients' identity in- and outside of the clinical context (Charon 2006). Thus, if we gather stories from individuals who choose to consistently use HAs and analyze those narratives, we can subesquently discern their identities. Recognizing different identity types can then ultimately lead to an understanding of certain decision-making processes and allow for the implementation of improved person-centered care for people who have been prescribed HAs (Epstein \& Street 2011). Person-centered care is a holistic approach to healthcare that places the person seeking care at the helm of their treatment. It is intended that the individual (and/or their family) will work collaboratively with a team of professionals to address needs of the individual's physical, psychological, social, and environmental wellbeing (see Grenness et al (2014) for details regarding the implementation of person-centered care in the field of audiology).

\section{Inconsistencies Between Patient and Provider Perceptions}

Despite the fact that HAs are efficacious (Ferguson et al. 2017; Ivory et al. 2009; Johnson et al. 2016), research exploring patients' subjective experiences with HAs (or the lack thereof) is minimal. To date, there have been a few notable exceptions pertaining to spouses of individuals diagnosed with occupational HL (Barker, Leighton, \& Ferguson, 2017; Hétu et al. 1988), older adults with HL who do not use HAs (Wallhagen 2010), adults' psychosocial experiences of HL (Barker et al., 2017; Heffernan, Coulson, Henshaw, Barry, \& Ferguson, 2016), and older adults 
with HL experiencing communication breakdowns (Hallberg \& Carlsson 1991). One study that directly addresses the HA experiences of individuals with HL is that of Bennett and colleagues (2018). In this study, they utilized concept mapping — a mixed-methods approach employing visual maps of the individual's and group's perspectives regarding targeted, HA topics (e.g., sound quality or management) — to explore the perspectives of hearing healthcare providers $(\mathrm{n}=$ $21)$ and HAs owners $(n=17)$ from Western Australia. Their findings revealed that the HAs

owners reported a number of struggles throughout their HA journey (e.g., HA management; HA sound quality and performance; feelings, thoughts, and behaviors surrounding HAs; HA information and training). Although the hearing healthcare providers also perceived the same struggles the patients reported experiencing, the providers judged the patients' struggles to be more detrimental to HA success than the patients perceived them to be. These findings are valuable because they not only provide subjective perspectives into HA use, but also suggest there is disconnect between audiologists' and patients' perspectives/experiences. Such a disconnect is concerning because professionals cannot offer appropriate, person-centered care and support without first attempting to identify and understand the patient's perspectives of the HA intervention process (Grenness et al 2014; Laplante-Lévesque et al. 2010). Gathering narratives from individuals with HL who use HAs is an important component in understanding how they self-identify. Identifying such identities can then, ideally, improve person-centered, hearing healthcare (Charon 2006; Grenness et al. 2014; Thompson et al. 2003).

\section{An Interpretive Narrative Approach}

When people face crises or must cope with difficulties - like those introduced with a diagnosis of HL in adulthood (e.g., in personal relationships (Wallhagen et al. 2004) and at work (Jennings \& Shaw 2008)) — they often turn to storytelling as a means to make sense of the 
disruption (Becker 1997; Koenig Kellas 2018). Storytelling is a sensemaking process that simultaneously reflects and (re)constructs individuals' identities (Matlis 2009; McAdams 1993; Scharp et al. 2018; Thomas 2014) and a number of scholars have linked people's ability to (re)construct their identity with emotional and physical wellbeing outcomes (e.g., McAdams 2006; see Koenig Kellas 2018). In other words, the type of identity people construct reflects their wellbeing. Westby and Culatta (2016) even argued that people who are able to construct coherent identities might be more likely to evolve into informed decision makers/problem solvers who are able to take control and responsibility for their lives. In this regard, identity construction has implications for both health outcomes and people's ability to live better lives.

Narrative scholars not only attend to reflection, but also the process of identity construction. These researchers take an interpretive narrative approach to better understand how people (re)imagine themselves after they have experienced major disruptions such as job loss (Pederson 2013), religious disaffiliation (Scharp \& Beck 2017), family crises (Thomas 2014), and - most relevant to this study - hearing loss (Scharp et al. 2018). Researchers who frame their scholarship in an interpretive narrative approach see people as storytelling beings and stories themselves as a mechanism by which people communicate a self that is becoming and incomplete, as opposed to a self that is fixed (Bamberg \& Georgakopoulou 2008; Koenig Kellas 2018). Thus, there is power in the performance of narrative and implications for how people create, repair, or destroy their sense of selves (Nelson 2001) particularly in the healthcare context (Gray 2009). Given the importance and potential of narrative in identity construction and the importance of those identities in making sense of health behavior, we pose the following question: What types of identities do people who have HL and consistently use HAs construct in their stories about diagnosis and treatment? 


\section{MATERIALS AND METHODS}

\section{Study Design}

This qualitative study employed a narrative approach.

\section{Participants}

Thirty adults ( $\mathrm{n}=20$ females; $\mathrm{n}=10$ males) participated in this study. We made an a priori decision to collect stories from 30 individuals based on the saturation points of other TNA (e.g., Pederson, 2014; Scharp et al., 2018; Scranton, 2015; Thomas, 2014) and to give us enough stories to reasonably engage in referential adequacy.

A hearing healthcare provider diagnosed sensorineural hearing loss (SNHL) and recommended at least one HA for each of the participants. The participants were diagnosed with SNHL ranging in degrees from mild to profound. These individuals ranged in age from 20 - 90 years $(M=62.03$ years; $S D=18.13)$. All participants resided in the U.S. and primarily identified as "not Hispanic or Latino" $(\mathrm{n}=29)$. Participants in the study met the following inclusion criteria: 1) self-identified as a HA user, 2) professionally diagnosed with SNHL, 3) prescribed HAs by a hearing healthcare provider, 4) reported wearing HAs during waking hours, and 5) reported typically functioning cognition, with no co-occurring speech or language disorders. Table 1 displays detailed demographics for the participants. Note, all participants wore bilateral HAs, apart from Phoebe \#26 who used a Phonak Bolero B90-PR HA on her left ear and a Cochlear Nucleus N5 processor on her right ear and Bailey \#23 who used a Phonak Audéo S Smart III solely on her left ear.

\section{Procedures}

The University's Institutional Review Board reviewed and approved the procedures for this study. 
Phase I. We recruited participants by distributing letters to patients from the university's hearing clinic; posting fliers in public spaces locally and in surrounding areas; posting information via social media and lab websites; and relying on word of mouth. Individuals expressed their interest in participating in the study by directly calling or emailing the lab. After determining the interested individual met the inclusion criteria, we sent a Qualtrics (2018) questionnaire via E-mail which included an informed consent, Health Insurance Portability and Accountability Act (HIPAA) release, demographic questions, and HA use questions. Participants who were unable to fill out the questionnaire online completed it with the help of a research assistant upon meeting for the interview. If a person did not feel comfortable answering any questions, they were not required to do so.

Phase II. We garnered participants' narratives, via a guide based on narrative and semistructured interviewing principles (see Langellier, 1989; McCracken, 1998). Narrative interviews are the least structured type of interview and allows participants to tell their stories their way. Interested readers can find the interview protocol and prompts in the Appendix or access the material at http://tandfonline.com/doi/suppl.

The first and third authors used this protocol to gather stories from the participants at their preferred location (e.g., research lab or local coffee shop) or via telephone. All interviews were recorded using either a Marantz Professional PMD661 MKII or a Tascam DR-05 portable handheld digital-audio recorder with a Shure Professional SM81-LC microphone. We compensated the participants for their time in cash or with an online-retailer gift card following the interview. The mean interview time was 36 minutes and 12 seconds, with a range of 10 minutes 12 seconds to 72 minutes 58 seconds. 
Phase III. After the completion of data collection, research assistants transcribed the recordings, which yielded 239 pages of single-spaced text. Research assistants used Microsoft Word on an Apple iMac or Dell OptiPlex 7040 personal computer running Express Scribe Transcription Software Pro v 6.10 paired with an INFINITY Foot Control IN-USB-2 transcription foot pedal and Sennheiser HD 280 Pro circumaural headphones for transcription. Research assistants replaced names and places mentioned by the participants with pseudonyms during the transcription process. Finally, we contacted each person's hearing healthcare provider to confirm their diagnosis of SNHL and collect specific data about their listening devices. These data can be found in Table 1.

\section{Data Analysis}

Because an interpretive narrative approach calls for researchers to examine narrative as both ontological and epistemological (Koenig Kellas 2018), we turned to thematic narrative analysis (TNA) as our method of data analysis (Riessman 2008) to categorize and understand the HA users' identities. TNA is the corresponding method when using an interpretive narrative approach (e.g., Petty 2017; Scharp et al. 2018; Scranton 2015). Riessman (2008) originally developed the method to examine narratives that are intact ${ }^{1}$, as opposed to identifying the themes within a narrative. Thus, the unit of analysis was the participant's story. Based on Riessman's conceptualization of TNA, we adapted thematic analysis procedures developed by Braun and Clarke (2006) to assign one identity to each HA user by engaging in the following five steps: (1) gaining familiarity with the data, (2) identifying emergent themes, (3) defining and naming the

\footnotetext{
${ }^{1}$ Keeping a story intact means we focused on identity types instead of coding for aspects of a person's story that stand a contextual to their more holistic experience. From these intact stories, one can expect a typology of some sort - a typology of identities (e.g., Pederson, 2014; Scranton, 2015; Thomas, 2014) or a typology of stories (e.g., Scharp, Thomas, Paxman, 2015) to emerge.
} 
themes, (4) generating emergent identities based on the ways the themes formed different patterns, and (5) locating evocative exemplars. To familiarize ourselves with the data, all authors read and re-read the corpus. Then, we identified patterns in the data that coalesced into themes. For example, the theme isolated emerged when HA users discussed feeling alone, isolated, left out, or like they were missing out on things because of their HL. We then explored the ways these themes formed a pattern that constituted the HA users' identities. For example, the themes isolated, fearful, defeated, and disappointed coalesced to form the griever identity. (A list of the themes that emerged and their corresponding identities can be found in Table 2.) Next, we examined the sampled corpus and selected examples from the individuals' narratives that best represented the identities, keeping entire stories largely intact to illustrate the overarching identity type. Finally, we looked at the corpus and retrospectively determined when saturation was met. Saturation, defined as the point where no new identities emerge, was reached at Interview 14 (Corbin \& Strauss 2008).

Verification procedures. To ascertain the validity of our narrative analysis, we engaged in five interrelated verification procedures: (1) peer debriefing, (2) investigator triangulation, (3) negative case analysis, (4) audit trail, and (4) exemplar identification (Lincoln \& Guba 1985). The third and fourth authors first engaged in an independent analysis, discussing the data, reasoning through differences, and coming to a consensus (i.e. peer debriefing). The first and second authors also conducted an independent analysis but met with the whole team to discuss their noted emergent findings (i.e. investigator triangulation; Lincoln \& Guba). We accounted for all of narratives within our analysis, meaning that each story corresponded to one of the identities. This meets the standard for negative case analysis which is the most rigorous form of verification (see Kidder, 1981). Through the entire process, we kept detailed notes of the 
analysis, discussions, and the decisions we made to pinpoint the emergent identity types (i.e. the audit trail). Finally, we selected evocative exemplars to illustrate the emergent identities (i.e. exemplar identification) and present them within.

\section{RESULTS}

Given that our qualitative study operated from an interpretive paradigm, quantitative findings (e.g., frequencies or descriptive statistics) are not reported within. Specifically, we checked themes against Owen's (1984) standards of a) recurrence, b) repetition, and c) forcefulness. We also used Braun and Clarke's (2006) standards for "what is a theme" to conduct our analysis. In concert with Owen (1984), this means we not only looked for how often something appeared but also the extent to which it was meaningful to a participant and the extent to which they devoted their time to discuss it in rich detail within their narrative. Thus, reporting frequencies erases the nuance of analysis (reducing it to a question of "how much" as opposed to a question of quality). Five identities emerged in the stories of the adult HA users: 1) the satisfied user, 2) the overcomer, 3) the dispassionate user, 4) the resigned user, and 5) the griever.

\section{Identities of Individuals with Hearing Loss who use Hearing Aids}

The satisfied user. Satisfied users are not fazed by the diagnosis of a SNHL and the prescription of HAs in any significant way; they perceive their HAs to be worthwhile. This identity emerged when people described their ability to easily accept their HL and acclimatize to their HAs. For example, Jasper described:

... and I was shocked [LAUGHTER] when I left the [audiologist's] office! Woah! The high frequencies are coming in big - and I'm a commuter cyclist, so I'm on my bike quite a bit and all of a sudden, I'm hearing cars, and the buzz. You know, the grinding on the street. And the one thing I was a little concerned about-you 
know, I could hear, but — there was no depth of —uh, what do I wanna say? Well depth of field — um, just I could hear a car, but I couldn't see where-you know? You know, I have to look in the rear view because, you know, I thought it was right behind me. But it — you know — was half a block down...you know one of the most fantastic experiences I had right off — and I mean this was like within the first week - cause I called his office and I told him I can't believe this; but d'm a gardener too and I was out in the garden pulling weeds and stuff and the chirpingthe bird chirping and the bees buzzing and I could see them in the tree a half a block away and I could just see them buzzing away just going nuts and I thought, "wow”. Oh I-you know-I was really shocked at how much I'd missed and was missing and-um—so that got me started. (Jasper, Interview \#3)

As Jasper narrated, HAs facilitated a noticeable difference in his daily living. Even though he experienced HAs initially as a minor inconvenience, he was able to easily devise short-term coping mechanisms before he fully adapted to his HAs in the long term. Satisfied users also often relayed a sense of amazement at the benefit their HAs added to their lives, as revealed in Jasper's narrative.

The overcomer. Unlike the satisfied user, the overcomer identity emerged from stories highlighting a number of obstacles that significantly disrupted the HA users' lives. These disruptions often included feelings of self-consciousness, embarrassment, and/or fear of negative evaluation (i.e. internalized and externalized stigma). Despite these setbacks, overcomers' stories often entailed being able to learn from and transcend such disruptions to construct a "new normal" for their lives (Buzzanell 2018). For example, one overcomer shared: 
Well, after I got through with the machinery situation (which without using any protection)...I started asking her [his wife] to repeat things. Alright, and this was about 12 years ago and that's when I went to an audiologist in [our home state] and I was told I had hearing loss and that I should think about getting hearing aids. The hearing aids that I did get at that time...were the albatross of hearing aids—almost the size of my earlobes - which has the eight inch tubes going around and I used to put them in when I went to work and I used to take them out the minute I got home...I went to work for [a large home improvement store] in the kitchen cabinet department and I think that's where-where I really realized the deficiency in hearing I had because [SIGH] my communication with potential customers was...I started writing down incorrect phone numbers, incorrect addresses and, um, I guess that's when I really realized that I had a problem. Um, I started leaving them [HAs] on longer at that time - almost till I went to bed. And I put them on in the morning when I got up, but (to me) in a sales position that I had, um, it was a must. Umsome of the most embarrassing things with the hearing aids-I [would be in] the middle of a discussion and all of the sudden "BEEP, BEEP, BEEP" - the battery would give me-an indication [that it was dying] and I used to hold out as long as possible. And I would say, "Excuse me, Mother Nature is calling me." I was embarrassed to, you know, change the batteries. So, I went in the bathroom and changed the batteries... The hearing aids were actually a key to my success in that position I had. Um, I had a very good career with [the store] and, um, I attribute that a lot to the hearing aids...it was a vanity situation I guess, like everybody else. No, I don't have hair and I'm not-I wasn't going to let it go to cover up the hearing 
aids. But then the more I started reading articles about young kids who have to wear hearing aids because the boom boxes, and blasting out the radios, and all that. You know, I felt —well, I'm not the only one. And then in a social group — started talking and you know, we're out and one of my good friends, a woman, she said, "I see you got hearing aids." I said, "Yeah." She said, "Well here, look at mine." You know, so the vanity situation kind of disappeared. (Bill, Interview \#12)

Bill's story conveys an initial embarrassment over wearing HAs, to the point where he did not feel comfortable changing the batteries in front of other people. However, when he found a community of others who also wore HAs, his story evolved. He no longer seemed embarrassed, but rather revealed feelings of comfort in newfound solidarity with others who use HAs.

The dispassionate user. The dispassionate user identity emerged from stories that conveyed little affect regarding the person's diagnosis of HL or their experience with hearing technology. While other stories included themes of disruption due to HL diagnosis or HA acclimatization or satisfaction with their HAs, the stories that made up the dispassionate user identity were void of any such experiences. For example, one user simply reported: ...my wife recommended that I get it [my hearing] checked out and I met somebody who I took a liking to and who was [an] audiologist. And, so, I decided to go with them and stayed with them for 10 - 12 years. Anything else? (Dennis, Interview \#18)

Unlike stories marked with emotion, Dennis discussed his experience with little affect. This is only important bearing in mind HL might be considered a significant disruption in 
someone's daily life. Similarly, Estelle's narrative reads as a relatively emotionless, factual report with little detail about her journey with HL and HAs:

I was diagnosed probably back in the ' 90 s and, um, I just was not able to hear people and understand them. And realizing hearing loss was a problem in the family, I decided I just needed to have hearing tests and get a hearing aid, so that I would be able to at least be able to hear as well as I thought that I might be able to. (Estelle, Interview \#2)

In this example, Estelle provided an account as if HL was expected and thus, consequently not a major issue. This finding alludes to the importance expectations could play in the experience of HL and HA use.

The resigned user. This identity emerged when individuals described feelings of resignation with their HAs. Although not all resigned users expressed exasperation, many conveyed their frustration with their HL or HAs. Such individuals told stories about multiple attempts to start and maintain HA use and the battles they faced to establish habits of consistent use. Put simply, resigned users reported using their HAs because they have to; not because they want to use them. Leslie, when describing her motivations for getting her HAs, shared:

And, like, I remember coming here [the University] when I was like three to get my hearing tested and stuff. I technically should have had hearing aids, like, throughout my entire life, but I didn't want to get bullied in like elementary, middle school, and high school [LAUGHTER] So, I just decided that like, I was like, [MOCKING TONE] "Oh, I'll be fine without 'em. Like, I've been-you know-fine this entire time. Like, I don't need hearing aids." And stuff. Um—and then in —uh, this last, um, spring semester, I was at the very beginning - I was in class and the - on like 
the first day the teacher asked a quiz question and he was like, "Pull out a piece of paper and then I'm going to ask you a question." So, like, you know, I had my piece of paper ready and I was ready to really, like, write whatever it was down. I look around and like everyone is writing something down, and I'm like, "Wait, what the heck? Like, Did he say it already?" And like he had said the entire quiz question, which was like an entire - it was like a sentence long and I had missed every single word. I didn't hear any of it. And, so, I like turned to the kid next to me and was like, "Wait what the heck? What are we supposed to be writing?" And then like he was like, "You're supposed to write the different parts of blah, blah, blah, blah blah.” And I was like, "Oh. Crap.” And, so, I like missed that entire quiz question and I was like really, really fed up with that. So, I was like, "Dang it. Like I am going to like at least try, like, do something." Because like I'm really, really tired of, like, missing important stuff in class? So, I have - I had a friend at the time who was doing audiology. And, so, she really like, really tried to like, push me to come here. And so, yeah. Then $\mathrm{d}$ got fit with hearing aids and it's been very interesting. (Leslie, Interview \#4)

As illustrated in this example, resigned users present their HA use as an obligation rather than a choice. HAs, then, were the price they had to pay for a particular desired outcome.

The griever. The last identity type to emerge from the data corpus was the griever. Grievers' stories included being in a state of mourning over their HL. In their stories, there is a sense that they have not fully accepted their HL, and wish their lives were different. Janice described: 
...I had — had, um, hearing loss, uh, at a very early age. I had measles and I was told later that, um, my ears were perfect except for that I had had a high fever and it, for lack of a better term, burned the nerve in my ear. So, it's a nerve deafness that I have. And as I said, I had it from a very early age. Now what's kind of interesting is that my sister also lost her hearing at an early age — at two [years old]. And so, um, she has the same nerve - nerve deafness that I do. But in terms of the, um — the, um, forming of our ears, they always told us that we were fine on that, uh, front. But it was always disappointing to me as I learned later that-you know-I could have been given some medication that I would not have had to deal with this my whole life, which hasn't always been easy [CRYING] I don't think people realize how emotional it is to have your hearing not be where everybody else's is at. And I know that there are a lot worse things, but hearing is communication. And I've always felt I've had to either catch up, do better, uh, be more attentive. I mean from the get-go, from the time I entered school til I left and retired. That was always a burden that was placed on me to make sure that the communication was occurring....and my hearing is going from a loss that is - you know-was more moderate to now more severe, which is scaring the hell out of me because I just don't know whether-you know - how long I'm gonna be able to hear... And I will say, the one thing I loved about retiring was that I didn't have to answer the damn phone anymore. I didn't have to hear anything. I didn't have to perform. But it does make your world feel a little smaller. I mean, just like today: I went to, um-the uh, concert and-you know-I, I come away with maybe $20 \%$ of what, what was presented. And you know that - that feels very discouraging to me...I would have much preferred to 
have my hearing my whole life. I feel like I would have accomplished more. (Janice, Interview \#14)

As illustrated in this example, grievers experience sadness and loss surrounding their HL and HA use. Unlike those who were able to over this difficult transition, people who constructed griever identities did not tell stories of redemption.

\section{DISCUSSION}

Understanding how a patient self-identifies is important for hearing healthcare providers because who a person believes themselves is intrinsically related to how they behave which has important implications for their treatment adherence (Kearney \& O'Sullivan 2003). In the present study, we used an interpretive narrative approach and determined the identities of adults with HL who consistently use HAs. It is our goal to ultimately describe the nuances of these identities in a way that can ultimately help the field of hearing healthcare better understand these individuals' decision-making processes and increase the probability of patient adherence resulting in consistent HA use. Through narrative analysis, we identified the following five identity types in the present study: 1) the satisfied user, 2) the overcomer, 3) the dispassionate user, 4) the resigned user, and 5) the griever. The theoretical implications and practical applications associated with each identity are highlighted throughout.

The findings of the present study illustrate the great deal of variability across adults' experiences with HL and HAs. For example, some adults appeared unfazed by the diagnosis of a HL and the prescription of HAs - particularly the satisfied users in the present study. These users were satisfied with their listening devices and told narratives that suggest they are comfortable identifying as a person with HL who uses HAs. Hecht's (1993) communication theory of identity (CTI) posits that people whose identities align with their behavior (e.g., I am a fighter, thus I will 
adapt to whatever life throws at me.) have less mental health issues and better relational outcomes with their support networks than individuals whose identities are out of sync with their behaviors (Jung \& Hecht 2004). This is important considering these factors were noted in the stories of the satisfied users and might help support continued, consistent HA use.

The second identity that emerged from the TNA was the overcomer and it dominated the present narrative corpus. People who constructed this identity learned from their distressing experience and constructed a "new normal” (Buzzanell 2018). This finding echoes existing research that documented people's ability to tell stories where they were able to overcome their challenges and thrive (Baerger \& McAdams 1999; Becker 1997). It is worthy to note that identities characterized by this type of resilience are often linked to better health outcomes (McAdams 2006; Koenig Kellas 2018). This identity has particular clinical relevance given its prevalence. For example, when a professional notes patient narratives and behavior reflecting feelings of self-consciousness or embarrassment (e.g., HA-use occurring only in the privacy of their own home) during the HA evaluation process, the patient may be at a crossroads in their audiological experience. At this point, depending on the person, such HA users could either triumph over the challenges associated with the listening devices (i.e. overcomer) and continue with consistent HA use or collapse under the early challenges and cease HA use. At this crossroads in the HA evaluation process the professionals can take action to ensure the patient develops resilience and rises to the barriers often associated with HAs. The professional can do so by employing a rehabilitative model of service delivery that emphasizes person-centered care (Erdman et al 1994; Epstein \& Street 2011; Grenness et al 2014). Most importantly, the professional should be mindful of gradually helping the patient build up their HA listening experience while providing counseling that both educates and empowers the patient (Ferguson et 
al. 2016). Emphasizing the benefits of continued HA use and ensuring that the individual has realistic expectations of their listening devices could be especially valuable at this point in their HA experience (Jerram \& Purdy 2001).

The dispassionate user provides remarkable insight that might inform clinical practice. Recall that this identity reflected little affect regarding the person's diagnosis of HL or their experiences with HAs. The narratives of the dispassionate users simply revealed the facts: HL detected. HA prescribed. HAs employed. There was no emotion or detail as one might expect to find in stories of HL. Thus, stories of the HL diagnosis and treatment process told with such little emotion and arguably low coherence, might be a cause for concern. This identity type is one that is relatively new to the literature and has only been recognized one other time to date. In Scharp and colleagues' (2018) work, they used online narratives (i. e. blogs) to explore the identities of parents who chose cochlear implantation for their children with HL and their TNA revealed an identity of the matter-of-fact narrator. Stories from these parents described their experiences with their children's HL diagnosis and surgical intervention with a surprisingly flat affect and absence of coherence, much as we see with the dispassionate users' stories of the present data corpus. The authors noted that narrative coherence represents the extent to which people tell an organized and meaningful story marked by congruence of affect and content (Fiese \& Sameroff 1999). Low narrative coherence correlates with low wellbeing (Labov 1999; Labov \& Waletsky 1967) and low wellbeing leads to poor health outcomes (Stewart-Brown 1998)—thus, regardless of why the dispassionate user narrated in this manner, the lack of coherence might indicate that they are at risk for later HA non-use. It is the hearing healthcare provider's duty to learn to recognize a dispassionate user and know when to employ more frequent follow-ups employing 
person-centered care and emphasizing counseling. Such clinical intervention might be key to ensuring long-term, continued HA use throughout adulthood.

The fourth identity was the resigned user. They used their HAs because they have to. These individuals' narratives revealed that they found their HL diagnosis and HA treatment as undesirable, but because of audibility's importance to communication, these people perceived HA use as inevitable. The resigned user identity is a predictable one given our cultural perspective of disease and disability in the U.S. and elsewhere, "The normative reaction is to make light of one's affliction, to carry on as usual, and as far as possible to adopt the behaviour appropriate to a healthy person" (Pollock 2002, p. 55), however this identity has not been documented before in the field of health communication. As a result, it is difficult to know exactly how these individuals will progress with their HAs. Given that people's identities are ever evolving, it is possible that these individuals are still working through their HL diagnosis and might eventually develop into grievers (see below), thus increasing the possibility of later HA nonuse. Alternatively, the resigned users might grow into overcomers who ultimately construct their new normal resulting in a positive HA response. It is the hearing healthcare provider's job to monitor the resigned user's HA treatment progress closely using data from complete audiological evaluations (including patient-report, such as the Revised Hearing Handicap Inventory (Cassarly et al 2019)), so that when a individual's HA progress is in doubt, the professional can provide the patient with individualized support both in- and outside of the clinic.

The final identity we noted was the griever. The griever identity included narratives of those individuals who have not fully accepted their HL and wish their lives were different. This identity is closely associated with a long-standing body of research in the field of HL, 
particularly work exploring the experiences of people identified with HL later in adulthood (e.g., Kyle et al. 1985; Meadow-Orlans 1991; Rutman 1989). In this early work, HL was “...viewed literally as the death of one's hearing; it also results in the death of one's former lifestyle, social relationships and personal identity." (Rutman 1989, p. 307) Thus it is not unusual that HL diagnosis yields a grief response. Contrary to the overcomer, these people told stories where they were not able to overcome their contaminated narrative (see McAdams 2006). In the context of the present study, these findings correspond with Heine and Browning's (2004) work, who found that adults reported that the diagnosis of HL alone made them different from people with normal hearing. Recognizing a griever might also help professionals provide better care for adults with HL by increasing emotional support (e.g., group aural rehabilitation) or realizing that such an individual is not ready to proceed with the next step in care (e.g., HA trial). Indeed, being able to recognize any of the identity types might facilitate better person-centered care and be especially helpful in instances where patients encounter additional roadblocks following the identification of HL like the loss of employment (Jennings \& Shaw 2008).

\section{Limitations and Future Directions}

As with all research, the present study has limitations. Firstly, because identities are constantly in flux, it is possible that the HA users' identities noted within will evolve over time. For example, a griever recently identified with HL might find a local HL support group and subsequently evolve into an overcomer before the year's end. Without a longitudinal dataset, we are unable to reflect on the influence of time on these individuals' identities. We also want to make note that there might be individuals who construct very different identities than those that emerged from the present narratives but did not feel comfortable or want to talk about their experiences with a stranger. As such, people who have more positive experiences with HL and 
HAs might be more likely to talk about their experiences and volunteer to participate in studies like this one. These factors limit the present study. It would be valuable to conduct a longitudinal study gathering stories from individuals upon the point of their initial diagnosis of HL forward. Such data would give insight into evolving identities associated with the treatment of HL and provide opportunities for the participants to become comfortable with and trusting of the interviewers.

The present study is also limited as a result of a participant sample that lacks diversity and, therefore, limits our ability to apply the identities across all individuals seeking hearing healthcare services. The study sample includes primarily White individuals, which is not representative of the deaf and hard-of-hearing community across the U.S. and elsewhere (Hoffman et al. 2017) and socioeconomic status was not noted during the study. It is likely that one's ethnicity, culture, and socioeconomic status all play a large part in both one's identity and whether or not one can even consider purchasing HAs, let alone adhering to recommended, daily use (Nieman et al. 2016). The range in the participants' ages at diagnosis and the interview should also be noted as a limitation. The youngest participants, at 22 and 25 years old, introduced a large age-gap within the sample, with $67 \%$ of the participants reporting their age at or above 65 years. It is likely that the consequences of a HL diagnosis at birth for a 22 -year-old participant are different from those of a 90-year-old who received a HL diagnosis last year. Finally, the current study is limited because the narratives were only gathered from people who are relatively satisfied and using their HAs. These people are not likely to require the same professional, emotional, and educational support from hearing healthcare providers as those who dismiss the recommendation and prescription for HAs (Ekberg et al. 2014). It is for this reason we are currently gathering more narratives from additional adults with HL—particularly those 
with HL who choose not to use HAs. Given that adult, HA non-users make up the largest percentage of individuals with HL in the U.S. (Chien \& Lin 2012), it is important to understand how these people self-identify if we want to improve HA uptake and change the face of hearing healthcare.

\section{Conclusions}

Understanding an individual's identity has important implications for person-centered healthcare (Grenness et al. 2014) because who a person believes themselves to be drives their behaviors and has repercussions for the diagnosis and treatment of their HL (Kearney \& O'Sullivan 2003). The present study begins to shed light on the identities of individuals with HL who use HAs: 1) the satisfied user, 2) the overcomer, 3) the dispassionate user, 4) the resigned user, and 5) the griever. The findings reveal valuable, new information about the identities of individuals with HL who utilize HAs. The findings are particularly helpful when considering their clinical and theoretical implications. Clinically speaking, the five identities that emerged from the narratives of consistent, adult HA users are important to professionals' holistic understanding of individuals who are diagnosed with HL and adhere to HA recommendations. Thus, these findings are a first step toward continued improvement in the implementation of person-centered healthcare in the field of audiology that caters to specific individuals' identities in an attempt to increase, facilitate, and maintain HA use. Theoretically speaking, these findings are a noteable first step in working toward a grounded theory of hearing aid use (Strauss \& Corbin 2008) that could provide important insights yielding successes in both the clinic and the laboratory. 


\section{References}

Baerger, D. R. \& McAdams, D. P. (1999). Life story coherence and its relation to psychological well-being. Narrat Inq, 9, 69-96. doi: 10.1075/ni.9.1.05bae

Bamberg, M., \& Georgakopoulou, A. (2008). Small stories as a new perspective in narrative and identity analysis. Text Talk, 28, 377 - 396. doi: 10.1515/text.2008.018

Barker, A. B., Leighton, P., \& Ferguson, M. A. (2017) Coping together with hearingloss: a qualitative meta-synthesis of the psychosocial experiences of people with hearing loss and their communication partners, Int J Audiol, 56, 297-305.

doi: $10.1080 / 14992027.2017 .1286695$

Becker, G. (1997). Disrupted Lives: How People Create Meaning in a Chaotic World. Berkeley, CA: University of California Press.

Bennett, R. J., Laplante-Lévesque, A., Meyer, C. J., et al. (2018). Exploring hearing aid problems: Perspectives of hearing aid owners and clinicians. Ear Hear, 39, 172-187. doi: 10.1097/AUD.0000000000000477.

Blackwell, D. L., Lucas, J. W., Clarke, T. C. (2014). Summary health statistics for United States adults: National health interview survey, 2012. Vital Health Stat. Series 10, Data from the National Health Survey, 260, 1-161.

Braun, V., \& Clarke, V. (2006). Using thematic analysis in psychology. Qual Res Psychol, 3, 77101. doi: 10.1191/1478088706qp063oa

Buzzanell, P. M. (2018). Organizing resilience as adaptive-transformational tensions. J Appl Commun Res, 46, 14-18. doi: 10.1080/00909882.2018.1426711

Cassarly, C., Matthews, L., Simpson, A., \& Dubno, J. (2019). The Revised Hearing Handicap Inventory and Screening tool based on psychometric reevaluation of the Hearing 
Handicap Inventories for the Elderly and Adults. Ear Hear. Advance online publication. doi: 10.1097/AUD.0000000000000746

Charon, R. (2006). Narrative medicine: Honoring the stories of illness. New York, NY: Oxford University Press.

Chien, W., \& Lin, F. R. (2012). Prevalence of hearing aid use among older adults in the United States. Arch Intern Med, 172, 292-293. doi: 10.1001/archinternmed.2011.1408

Ciorba, A., Bianchini, C., Pelucchi, S., et al. (2012). The impact of hearing loss on the quality of life of elderly adults. Clin Interv Aging, 7, 159. doi: 10.2147/CIA.S26059

Corbin, J., \& Strauss, A. (2008). Basics of Qualitative Research: Techniques and Procedures for Developing Grounded Theory. Thousand Oaks, CA: Sage.

Ekberg, K., Grenness, C., \& Hickson, L. (2014). Addressing patients' psychosocial concerns regarding hearing aids within audiology appointments for older adults. Am J Audiol, 23, 337-350. doi: 10.1044/2014_AJA-14-0011

Epstein, R.M., \& Street, R. L. (2011). The values and value of patient-centered care. Ann Fam Med, 9, 100-103, doi: 10.1370/afm.1239

Erdman, S. A., Wark, D. J., \& Montano, J. (1994). Implications of service delivery in audiology. J Acad Rehab Audiol, 27, 45-60.

Fiese, B. H., \& Sameroff, A. J. (1999). The family narrative consortium: A multidimensional approach to narratives. In Fiese B. H., Sameroff A. J., Grotevant H. D., Wamboldt F. S., Dickstein S., \& Fravel D. L. (Eds.), The Stories that Families Tell: Narrative Coherence, Narrative Interaction, and Relationship Beliefs (pp. 1-36). Monogr Soc Res Child Dev, 64, Malden, MA: Blackwell. 
Ferguson, M. A., Kitterick, P. T., Chong, L., Edmondson-Jones, M., Barker, F., \& Hoare, D. J. (2017). Hearing aids for mild to moderate hearing loss in adults. Cochrane Database of Systematic Reviews 2017, Issue 9, doi: 10.1002/14651858.CD012023.pub2

Ferguson, M. A., Woolley, A., \& Munro, K. J. (2016). The impact of self-efficacy, expectations, and readiness on hearing aid outcomes. Int J Audiol, 55, S34-S41. doi: $10.1080 / 14992027.2016 .1177214$

Gray, J. B. (2009). The power of storytelling: Using narrative in the healthcare context. $J$ Commun Healthc, 2, 258-273. doi: 10.1179/cih.2009.2.3.258

Grenness, C., Hickson, L., Laplante-Lévesque, A., et al. (2014). Patient-centered care: A review for rehabilitative audiologists. Int J Audiol, 53, S60-S67. doi: $10.3109 / 14992027.2013 .847286$

Hallberg, L. R. M., \& Carlsson, S. G. (1991). A qualitative study of strategies for managing a hearing impairment. Int $J$ Audiol, 25,201-211. doi: 10.3109/03005369109079853

Hecht, M. L. (1993). 2002-a research odyssey: Toward the development of a communication theory of identity. Commun Monogr, 60, 76-82. doi: 10.1080/0363775909376297

Heine, C. \& Browning C. J. (2004). The communication and psychosocial perceptions of older adults with sensory loss: A qualitative study. Ageing Soc, 24, 113-130. doi: 10.1017/S0144686X03001491

Heffernan, E., Coulson, N. S., Henshaw, H., Barry, J. G., \& Ferguson, M.

A. (2016) Understanding the psychosocial experiences of adults with mild-moderate hearing loss: An application of Leventhal's self-regulatory model. Int J Audiol, 55, S3S12, doi: 10.3109/14992027.2015.1117663 
Hétu, R., Riverin, L., Lalande, N., et al. (1988). Qualitative analysis of the handicap associated with occupational hearing loss. Int J Audiol, 22, 251-264. doi:

$10.3109 / 03005368809076462$

Hoffman, H. J., Dobie, R. A., Losonczy, K. G., et al. (2017). Declining prevalence of hearing loss in us adults aged 20 to 69 years. JAMA Otolaryngol Head Neck Surg, 143, 274-285. doi: $10.1001 /$ jamaoto.2016.3527

Ivory, P. J., Hendricks, B. L., Van Vliet, D., et al. (2009). Short-term hearing aid benefit in a large group. Trends Amplif, 13, 260-280. doi: 10.1177/1084713809354902

Jennings, M. B., \& Shaw, L. (2008). Impact of hearing loss in the workplace: Raising questions about partnerships with professionals. Work, 30, 289-295.

Jerram, J. C. K., \& Purdy, S. C. (2001). Technology, expectations, and adjustment to hearing loss: Predictors of hearing aid outcome. J Am Acad Audiol, 12, 64-79.

Johnson, C. E., Danhauer, J. L., Ellis, B. B., et al. (2016). Hearing aid benefit in patients with mild sensorineural hearing loss: A systematic review. J Am Acad of Audiol, 27, 293-310. doi: $10.3766 /$ jaaa. 14076

Jung, E., \& Hecht, M. L. (2004). Elaborating the communication theory of identity: Identity gaps and communication outcomes. Commun $Q, 52,265-283$. doi:

$10.1080 / 01463370409370197$

Kearny, M. H, \& O’Sullivan, J. (2003). Identity shifts as turning points in health behavior change. West J of Nurs Res, 25, 134-152. doi: 10.1177/0193945902250032

Kidder, L. H. (1981). Qualitative research and quasi-experimental frameworks. In B. Brewer and B. Collins (Eds.), Scientific inquiry and the social sciences (pp. 380-382). San Francisco, CA: Jossey-Bass. 
Koenig Kellas, J. (2018). Communicated narrative sense-making theory: Linking storytelling and well-being. In D. O. Braithwaite, E. A. Suter, \& K. Floyd (Eds.), Engaging theories in family communication (pp. 62-74). New York, NY: Routledge.

Kyle, J. G., Jones, L. G., \& Wood, P. L. (1985). Adjustment to acquired hearing loss: A working model. In H. Orlans (Ed.) Adjustment to adult hearing loss. San Diego, CA: Hill Press.

Labov, W. (1999). The transformation of experience in narrative. In A. Jaworski and N.

Coupland (Eds.), The discourse reader (pp. 221-235). New York, NY: Routledge.

Labov, W., \& Waletzky, J. (1967). Narrative analysis: Oral versions of personal experience. In J. Helm (Ed.), Essays on the verbal and visual arts. Seattle, WA: University of Washington Press.

Langellier, K. M. (1989). Personal narratives: Perspectives on theory and research. Text and Performance Quarterly, 9, 243-276. doi:10.1080/10462938909365938

Laplante-Lévesque, A., Hickson, L., \& Worrall, L. (2010). A qualitative study of shared decision making in rehabilitative audiology. $J$ Acad Rehabil Audiol, 27-43.

Lin, F. R., Yaffe, K., Xia, J., et al. (2013). Hearing loss and cognitive decline in older adults. JAMA Intern Med, 173, 293. doi: 0.1001/jamainternmed.2013.1868

Lincoln, Y. S., \& Guba, E. G. (1985). Naturalistic Inq. Newbury Park, CA: Sage.

Maitlis, S. (2009). Who am I now? Sensemaking and identity in posttraumatic growth. In L. M. Roberts \& J. E. Dutton (Eds.) Exploring Positive Identities and Organizations: Building a Theoretical and Research Foundation (pp. 47-76). New York, NY: Psychology Press.

McAdams, D. P. (1993). The Stories We Live By: Personal Myths and the Making of the Self. New York, NY: Morrow. 
McAdams, D. P. (2006). The Redemptive Self: Stories Americans Live By. New York, NY: Oxford University Press.

McCormack, A., \& Fortnum, H. (2013). Why do people fitted with hearing aids not wear them? Int J Audiol, 52, 360-368. doi: 10.3109/14992027.2013.769066

McCracken, G. (1998). The long interview. Newbury Park, CA: Sage.

Meadow-Orlans, K. (1991). Social and psychological effects of hearing loss in adulthood: A literature review. In H. Orlans (Ed.) Adjustment to Adult Hearing Loss (pp. 35-57). San Diego, CA: Singular Publishing Group.

Nelson, H. L. (2001). Damaged Identities: Narrative Repair. Ithica, NY: Cornell University Press.

Nieman, C. L., Marrone, N., Szanton, S. L., et al. (2016). Racial/ethnic and socioeconomic disparities in hearing health care among older Americans. J Aging Health, 28, 68-94. doi: $10.1177 / 0898264315585505$

Owen, W. F. (1984). Interpretive themes in relational communication. Quart J Speech, 70, 274 287. doi: $10.1080 / 00335638409383697$

Paddam, A., Barnes, D., Langdon, D. (2010). Constructing vignettes to investigate anger in multiple sclerosis. Nurs Res 17, 60-73. doi: 10.7748/nr2010.01.17.2.60.c7463

Pederson, J. R.(2013). Disruptions of individual and cultural identities: How online stories of job loss and unemployment shift the American Dream. Narrat Inq, 23, 302-322. doi: 10.1075/ni.23.2.05ped

Petty, J. (2017). Creating stories for learning about the neonatal care experience through the eyes of student nurses: An interpretive, narrative study. Nurse Educ Today, 48, 25-32. doi: 10.1016/j.nedt.2016.09.007 
Pollock, K. (2002). Attitude of mind as a means of resisting illness. In A. Radley (Ed.) Worlds of Illness: Biographical and cultural perspectives on health and disease (pp. 49-70). New York, NY: Routledge.

Qualtrics. (Version 22) [Computer Software]. (2018). Provo, Utah: Qualtrics.

Riessman, C. K. (2008). Narrative Methods for the Human Sciences. Thousand Oaks, CA: Sage Publications.

Rutman, D. (1989). The impact and experience of adventitious deafness. Am Ann Deaf, 134, 305311. doi: 10.1353/aad.2012.0523

Scharp, K. M., Barker, B. A., Rucker, S. N., \& Jones, H. D. (2018).Exploring the identities of hearing parents who chose cochlear implantation for their children with hearing loss. The J Deaf Stud Deaf Educ, 23, 131-139. doi: 10.1093/deafed/enx060

Scharp, K. M. \& Beck, A. L. (2017). “Losing my religion”: Identity (re)constructions in Mormon exit narratives. Narrat Inq, 27, 132-148. doi: 10.1075/ni.27.1.07sch

Scranton, A. (2015). "I won't change who I am for anyone": Muslim women's narrative identities. Narrat Inq, 25, 148-165. doi: 10.1075/ni.25.1.09scr

Stewart-Brown, S. (1998). Emotional wellbeing and its relation to health. Br Med J, 317, 16081609.

Thomas, L. J. (2014). “Once a foster child ... ”: Identity construction in former foster children's narratives. Qual Res Rep Commun, 15, 84-91. doi: 10.1080/17459435.2014.955596

Thompson, T. L., Dorsey, A. M., Miller, A. M. et al. (Eds). (2003) Handbook of Health Communication. Mahwah, NJ: Lawrence Erlbaum Associates.

Wallhagen, M. I. (2010). The stigma of hearing loss. Gerontologist, 50, 66-75. doi: 10.1093/geront/gnp107 
Wallhagen, M. I., Strawbridge, W. J., Shema, S. J., et al. (2004). Impact of self-assessed hearing loss on a spouse: A longitudinal analysis of couples. J Gerontol: Series B, 59, S190-S196. doi: 10.1093/geronb/59.3.S190

Westby, C. \& Culatta, B. (2016). Telling tales: Personal event narratives and life stories. Lang Speech Hear Serv Sch, 47, 260-282. doi: 10.1044/2016_LSHSS-15-0073 


\section{Acknowledgements}

We would like to thank everyone who felt comfortable sharing their stories with us. Without people like them, this research would not be possible. We are also grateful to Nicole Trusty, Emma Brown, Dane Whittaker, and the members of the Aural Rehabilitation Lab for all the time they spent transcribing narrative interviews. 
Table

Table 1

Participant demographic and hearing aid use data.

\begin{tabular}{|c|c|c|c|c|c|c|c|}
\hline Participant & Age & Gender & Ethnicity & $\begin{array}{c}\text { Age at } \\
\text { HL } \\
\text { Diag- } \\
\text { nosis } \\
\end{array}$ & $\begin{array}{c}\text { PTA3 }_{3} \\
\text { (dB } \\
\text { HL) }\end{array}$ & Hearing Device(s) & HA Use \\
\hline Lily, \#1 & 67 & $\mathrm{~F}$ & $\begin{array}{c}\text { not } \\
\text { Hispanic } \\
\text { or Latino }\end{array}$ & - & 26.6 & Siemens Carat $5 b x$ & ...about half... \\
\hline Estelle, \#2 & 83 & $\mathrm{~F}$ & $\begin{array}{l}\text { not } \\
\text { Hispanic } \\
\text { or Latino }\end{array}$ & 56 & 56.6 & $\begin{array}{c}\text { Oticon Ino Pro Mini } \\
\text { BTE }\end{array}$ & during all... \\
\hline Jasper, \#3 & 67 & M & $\begin{array}{c}\text { not } \\
\text { Hispanic } \\
\text { or Latino }\end{array}$ & 43 & 33.3 & Audéo Q50 & during most... \\
\hline Leslie, \#4 & 20 & $\mathrm{~F}$ & $\begin{array}{c}\text { not } \\
\text { Hispanic } \\
\text { or Latino }\end{array}$ & 2 & $e^{36.6}$ & $\begin{array}{c}\text { Starkey Z Series RIC } \\
i 110\end{array}$ & during most... \\
\hline Abigail, \#5 & 67 & $\mathrm{~F}$ & $\begin{array}{c}\text { not } \\
\text { Hispanic } \\
\text { or Latino }\end{array}$ & 410 & 50 & Signia Pure 5px & during all... \\
\hline Wendy, \#6 & 70 & $\mathrm{~F}$ & $\begin{array}{l}\quad \text { not } \\
\text { Hispanic } \\
\text { or Latino }\end{array}$ & - & 25 & Resound Linx $x^{2} 9$ & during most... \\
\hline Tiffany, \#7 & 55 & $\mathrm{~F}$ & $\begin{array}{l}\text { not } \\
\text { Hispanic } \\
\text { or Latino }\end{array}$ & 41 & 38.3 & Resound Linx $x^{2} 9$ & sometimes... \\
\hline Hannah, \#8 & 72 & $\mathrm{~F}$ & $\begin{array}{l}\text { not } \\
\text { Hispanic } \\
\text { or Latino }\end{array}$ & 62 & 21.6 & Signia Pure $5 b x$ & during most... \\
\hline Jill, $\# 9$ & 73 & $\mathrm{~F}$ & $\begin{array}{l}\text { not } \\
\text { Hispanic } \\
\text { or Latino }\end{array}$ & 69 & 26.6 & Signia Pure 5px & during all... \\
\hline Alex, \#10 & 67 & $\mathrm{~F}$ & $\begin{array}{c}\text { not } \\
\text { Hispanic } \\
\text { or Latino }\end{array}$ & 62 & 33.3 & $\begin{array}{c}\text { Siemens Cellion Pure } \\
\text { RIC }\end{array}$ & during most... \\
\hline John, \#11 & 65 & M & $\begin{array}{l}\text { not } \\
\text { Hispanic } \\
\text { or Latino }\end{array}$ & 28 & 30 & $\begin{array}{c}\text { Siemens Carat7bx }+ \\
\text { EasyTek }\end{array}$ & during most... \\
\hline
\end{tabular}




\begin{tabular}{|c|c|c|c|c|c|c|c|}
\hline Participant & Age & Gender & Ethnicity & $\begin{array}{l}\text { Age at } \\
\text { HL } \\
\text { Diag- } \\
\text { nosis } \\
\end{array}$ & $\begin{array}{l}\text { PTA3 } \\
\text { (dB } \\
\text { HL) }\end{array}$ & Hearing Device(s) & HA Use \\
\hline Bill, \#12 & 72 & M & $\begin{array}{c}\text { not } \\
\text { Hispanic } \\
\text { or Latino }\end{array}$ & 58 & 51.6 & $\begin{array}{c}\text { Oticon Nera Pro mini } \\
\text { BTE }\end{array}$ & during all... \\
\hline Beth, \#13 & 22 & $\mathrm{~F}$ & $\begin{array}{l}\text { not } \\
\text { Hispanic } \\
\text { or Latino }\end{array}$ & birth & 60 & Siemens Carat $5 b x$ & during all... \\
\hline Janice, \#14 & 70 & $\mathrm{~F}$ & $\begin{array}{l}\text { not } \\
\text { Hispanic } \\
\text { or Latino }\end{array}$ & 5 & 60 & Bernafon Chinos $7 C P$ & during all... \\
\hline Brad, \#15 & 72 & M & $\begin{array}{l}\text { not } \\
\text { Hispanic } \\
\text { or Latino }\end{array}$ & 51 & - & $\lambda=$ & during all... \\
\hline Fred, \#16 & 70 & M & $\begin{array}{l}\text { not } \\
\text { Hispanic } \\
\text { or Latino }\end{array}$ & 59 & 18.3 & Resound Dot 20 RIC & during most... \\
\hline George, \#17 & 72 & M & $\begin{array}{l}\text { not } \\
\text { Hispanic } \\
\text { or Latino }\end{array}$ & 68 & 23.3 & Phonak Audéo B70-R & sometimes... \\
\hline Dennis, \#18 & 90 & M & $\begin{array}{l}\text { not } \\
\text { Hispanic } \\
\text { or Latino }\end{array}$ & 78 & - & $\begin{array}{c}\text { Micro-tech Triumph } \\
W 20\end{array}$ & during all... \\
\hline Monica, \#19 & 25 & $\mathrm{~F}$ & $\begin{array}{l}\quad \text { not } \\
\text { Hispanic } \\
\text { or Latino }\end{array}$ & 2 & 60 & Siemens Carat $7 b x$ & during all... \\
\hline Tom, \#20 & 55 & M & $\begin{array}{c}\text { not } \\
\text { Hispanic } \\
\text { or Latino }\end{array}$ & 45 & 31.6 & Siemens Pure 301 & during all... \\
\hline Roger, \#21 & 88 & $M$ & $\begin{array}{c}\text { not } \\
\text { Hispanic } \\
\text { or Latino }\end{array}$ & 59 & 68.3 & Phonak Naida V70-SP & during all... \\
\hline Jane, \#22 & 70 & $\mathrm{~F}$ & $\begin{array}{l}\text { not } \\
\text { Hispanic } \\
\text { or Latino }\end{array}$ & 56 & 48.3 & $\begin{array}{l}\text { Oticon Ria Pro } \\
\text { MiniRITE }\end{array}$ & during all... \\
\hline Bailey, \#23 & 33 & $\mathrm{~F}$ & $\begin{array}{l}\text { not } \\
\text { Hispanic } \\
\text { or Latino }\end{array}$ & 5 & 35 & $\begin{array}{c}\text { Phonak Audéo S Smart } \\
\text { III (AS) }\end{array}$ & during all... \\
\hline Emily, \#24 & 49 & $\mathrm{~F}$ & $\begin{array}{c}\text { not } \\
\text { Hispanic } \\
\text { or Latino } \\
\end{array}$ & 4 & 48.3 & $\begin{array}{c}\text { Phonak Audéo } Q 70 \\
\text { BTE }\end{array}$ & during all... \\
\hline
\end{tabular}




\begin{tabular}{|c|c|c|c|c|c|c|c|}
\hline Participant & Age & Gender & Ethnicity & $\begin{array}{c}\text { Age at } \\
\text { HL } \\
\text { Diag- } \\
\text { nosis } \\
\end{array}$ & $\begin{array}{c}\text { PTA3 } \\
\text { (dB } \\
\text { HL) }\end{array}$ & Hearing Device(s) & HA Use \\
\hline Phil, \#25 & 54 & M & $\begin{array}{l}\quad \text { not } \\
\text { Hispanic } \\
\text { or Latino }\end{array}$ & 13 & 35 & $\begin{array}{c}\text { Oticon Nera Pro Mini } \\
\text { BTE }\end{array}$ & during all... \\
\hline Phoebe, \#26 & 40 & $\mathrm{~F}$ & $\begin{array}{l}\text { Hispanic } \\
\text { or Latino }\end{array}$ & birth & $\begin{array}{c}72.5 \\
(\mathrm{NR} \text { at } \\
2 \mathrm{k})\end{array}$ & $\begin{array}{l}\text { Phonak Bolero B90- } \\
\text { PR \& Cochlear } \\
\text { Nucleus } 5 \text { Processor }\end{array}$ & during all... \\
\hline Amy, \#27 & 72 & $\mathrm{~F}$ & $\begin{array}{c}\text { not } \\
\text { Hispanic } \\
\text { or Latino }\end{array}$ & 53 & 58.3 & Starkey S Series 7 & during most... \\
\hline Thelma, \#28 & 66 & $\mathrm{~F}$ & $\begin{array}{l}\text { not } \\
\text { Hispanic } \\
\text { or Latino }\end{array}$ & - & 11.6 & $\begin{array}{c}\text { Phonak Audéo B70 } \\
\text { Direct }\end{array}$ & ...about half... \\
\hline Sue, \#29 & 77 & $\mathrm{~F}$ & $\begin{array}{c}\text { not } \\
\text { Hispanic } \\
\text { or Latino }\end{array}$ & 70 & 36.6 & $\begin{array}{l}\text { Starkey Z Series il00 } \\
\text { RIC }\end{array}$ & during all... \\
\hline Pam, \#30 & 58 & $\mathrm{~F}$ & $\begin{array}{l}\text { not } \\
\text { Hispanic } \\
\text { or Latino }\end{array}$ & 22 & 46.6 & $\begin{array}{l}\text { Oticon Ino Pro } \\
\quad \text { miniRITE }\end{array}$ & during most... \\
\hline
\end{tabular}

Note: participant $=$ participant's pseudonym and interview number for the present study; ages are reported in years; $\mathrm{F}=$ female; $\mathrm{M}=$ male; $\mathrm{PTA}_{3}=$ pure-tone average of $500 \mathrm{~Hz}, 1000 \mathrm{~Hz}$, and $2000 \mathrm{~Hz}$ for better ear; HA use = hearing aid usage as reported by the participant via the initial demographic survey (i.e. during all waking hours, during most waking hours, during about half of my waking hours, sometimes during waking hours, never during waking hours); - = data unavailable; participant Brad, \#15 could not recall the name or practice of his audiologist. 
Table 2

Reoccurring narrative themes and the corresponding identities.

reoccurring narrative themes corresponding identities

amazed, internally-driven

the satisfied user

personal growth, positive doctor-patient relationship, advocate, self-conscious

rational, recognizes benefit, realistic

the dispassionate user

fed-up

the overcomer

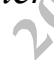

象

the resigned user

disappointed, isolated

the griever 